Editorial

\title{
The Potential of Serious Games to Solve Water Problems: Editorial to the Special Issue on Game-Based Approaches to Sustainable Water Governance
}

\author{
Wietske Medema ${ }^{1, *(\mathbb{D}}$, Igor Mayer ${ }^{2} \mathbb{D}$, Jan Adamowski ${ }^{1}$, Arjen E.J. Wals ${ }^{3}$ and Chengzi Chew ${ }^{4}$ \\ 1 Department of Bioresource Engineering, McGill University, 21111 Lakeshore, Ste Anne de Bellevue, \\ QC H9X3V9, Canada; jan.adamowski@mcgill.ca \\ 2 Academy for Digital Entertainment, Breda University of Applied Sciences, Monseigneur Hopmansstraat 1, \\ 4817 JT Breda, The Netherlands; i.s.mayer@hotmail.com \\ 3 Department of Social Sciences, Education and Learning Sciences, Wageningen University, \\ 6706 KN Wageningen, The Netherlands; arjen.wals@wur.nl \\ 4 Serious Games at DHI, Agern Allé 5, 2970 Hørsholm, Denmark; czc@dhigroup.com \\ * Correspondence: wietske.medema@mcgill.ca; Tel.: +1-(310)-480-5204
}

Received: 10 November 2019; Accepted: 25 November 2019; Published: 5 December 2019

\begin{abstract}
In this editorial, the authors (and guest editors) introduce the Special Issue titled Understanding Game-based Approaches for Improving Sustainable Water Governance: The Potential of Serious Games to Solve Water Problems. The authors take another look at the twelve contributions, starting from the subtitle question: what is the potential? The authors summarize the insights and give directions for future research.
\end{abstract}

Keywords: game-based learning; integrated water resource management (IWRM); natural resource management; simulation; serious game; social learning; stakeholder collaboration; sustainability; water governance

\section{Introduction}

In 2018 and 2019, Water (MDPI) published twelve articles in a Special Issue titled Understanding Game-Based Approaches for Improving Sustainable Water Governance: The Potential of Serious Games to Solve Water Problems. This editorial gives an introduction to the Special Issue, with insights and directions for future research.

A grant provided by the Social Sciences and Humanities Research Council of Canada (SSHRC) in 2015 (see below) brought the Guest Editors together in the UPSWING project: Understanding game-based approaches for improving sustainable water governance and stakeholder collaboration in the Great Lakes-St. Lawrence River Basin. One of the proposed actions in the project was to collect and bundle a wide range of experiences with serious games for water management.

From the literature, we already knew that the terminology around serious games is extensive: applied games, simulation-games, serious games, interactive and social simulations, gamified approaches, even Virtual and Augmented Reality (VR/AR) and more. Furthermore, game characteristics, genre and styles are often used to describe the approach: a role-playing game, a computer-supported interactive simulation, digital game, board game, etc. Having worked in water management, learning and games for quite a few years, we also knew that the topic could be approached from different angles: i.e., the subject matter, the application area, the design of the game, the game technology, the research or evaluation methodology and the learning. In short, it would not be easy to bring these diverse aspects together coherently. 
In 2017, we issued a call for papers. In the following years, more than twenty manuscripts were submitted, twelve of which were published after peer review and revision. The majority of papers are empirical case studies. Two papers are an inventory and analysis of existing games. Three papers are conceptual and reflective; seven papers are case and field studies. One paper synthesizes the results [1]. The Special Issue was closed in September 2018. Table 1 gives a short overview of the papers in the Special Issue.

Table 1. Overview of papers in the Special Issue.

\begin{tabular}{l} 
Game Analysis \\
\hline 1. Galván-Pérez et al. evaluate twenty educational videogames about water sustainability on quality of their \\
content, game-play and educational value [2]. They conclude that water games in the simulation genre, like \\
managing a city or region, are highly appropriate for learning. \\
2. Rodela, Ligtenberg and Bosma focus on an inventory of serious games in natural resource and \\
environmental governance to conceptualize and discuss different uses: for research, learning and \\
intervention [3]. They use examples from the literature and their own experiences with a game about shrimp \\
farming in the Mekong Delta, Vietnam, to develop a framework for the design and evaluation of serious games \\
as learning-based intervention.
\end{tabular}

\section{Policy-Making and Social Learning}

1. At the science-policy interface, Zhou and Mayer reconstruct the different frames that policymakers and analysts in the Netherlands and China have about the use and usefulness of models, simulations and games [4]. They demonstrate that social learning is only one of five different perspectives on the use of serious games, with others focusing on bureaucratic alignment, gaining stakeholder support and reducing uncertainty or emotions. 2. Marini et al. aim to understand the relationship between social learning and serious games in a context of IWRM [5]. They argue that Schwarz' theory on transcendental values (i.e., beyond self-interest) provides a foundation for understanding social learning in IWRM, managing competing values and working towards long-term collaboration. This gives guidance for the design and use of serious games.

3. Aubert, Medema and Wals take up the question 'why' games are beneficial (or not) for social learning in IWRM [1]. They develop a framework for design and suggest opportunities for future research.

\section{CASE and Field Studies}

4. Magnuszewski et al. present the initial results of piloting a social-simulation game, called Lord of the Valley [6]. They study the interrelations and interactions among the various stakeholders in a simulated river basin, observed during three sessions in Poland.

5. Gomes et al. report on the design, use and results of a social simulation game on the topic of drinking water, used for capacity building in a peri-urban community in Bangladesh [7]. The game combines game-theoretic models, with a board game and role play, and has been played with actual stakeholders living in a village near Kulna. They conclude that the game-based intervention successfully increased the understanding of the local stakeholders about the problems, solutions and institutions.

6. Ferrero, Bichai and Rusca report on the learning of students at IHE, Delft, the Netherlands in a role-playing game on drinking-water safety plans, in particular for public-health protection in drinking-water safety [8]. They demonstrate how and why the game helps the players to understand the governance process and the negotiation among stakeholders that it requires.

7. Susnik et al. show how serious games are designed and used for twelve case studies in the ongoing SIM4NEXUS project [9]. This project aims to integrate water-food-energy-climate for a resource-efficient Europe. The gaming approach combines system dynamics with the game AquaRepublica as a front end. The authors present the design and experiences of a pilot study in Sardinia, Italy.

8. Khoury et al. report on the design and use of a serious game for flood mitigation in a United Kingdom village [10]. They connect their approach to 'citizen science', shared vision planning and give evidence for an informative and transformative effect of the game-play. The serious game uses a 3D virtual table.

9. Keijser et al. used a board game for Maritime Spatial Planning (MSP) at the local, national and transnational level in a European context [11]. The authors organized 19 game sessions, with players of different backgrounds and familiarity to the topic. They report on the satisfaction, learning and uptake of the MSP Challenge board game, measured through questionnaires and observations.

10. Jean et al. aim to understand games as planning support systems [12]. They evaluated a computersupported simulation-game using Maritime Spatial Planning, used with students and a few practitioners in Canada. The game was evaluated with audio-visual analysis of player interactions of individual and group learning. 


\section{Starting Points}

The Special Issue was initiated from three perspectives:

1. A growing awareness on the urgency of water resources issues and the complexity of integrated water (resource) management;

2. An emerging paradigm that claims that the governance of natural resources, including water, benefits from a social learning approach;

3. A growing interest in the use of simulation games as a way to instrumentalize social learning.

Although each of the three perspectives are fairly well described in the literature, the questions at their intersection are not well conceptualized and studied. We had four main questions from the start:

1. How are social learning and game-based learning connected? What are the theories and concepts that tie them together?

2. What games are applied in sustainability, natural resource management and water? For what purpose are they used?

3. What is the function or role of games at the science-policy interface? What do policy makers and stakeholders themselves think about using simulations, games and play for policy making?

4. Does serious game-play have an impact on social learning in water management, and how can we observe or measure that?

\section{Why Serious Games for Water Management?}

This Special Issue postulates that water management and serious games are connected through complexity and social learning. The line of reasoning, nicely reflected in the twelve contributions, can be summarized as follows.

\subsection{The Urgency of the Matter; Games as Drivers for Change}

In a global context of climate change, degradation of ecosystems and depletion of natural resources, the availability and access of water for nature, consumption and production, are of imminent concern. In all parts of the world, droughts, floods and drinking-water quantity and quality are high on the societal and political agendas. To prepare the way for the change that is urgently needed, persuasive communication, education and involvement of stakeholders in society is necessary. Here, games and other media can be of use, for instance to reach a younger generation, or to bring stakeholders into a dialogue. Therefore, many organizations concerned with sustainability and water have taken the initiative to develop games with a persuasive or learning message. This is well reflected in the two journal articles about serious and persuasive games for sustainability, natural resource management and water [2,3]. The authors of the field-study articles also clearly convey this sense of urgency for sustainability.

\subsection{The Complexity of Water Management: Seeing the Bigger Picture}

Water (resource) systems are of an intricate complexity. They are a messy entanglement of hydrological aspects, geographical scales, time horizons, cause-effect relations, ecologies, human activities and much more. Problems with water are very grass roots, but their root causes are often regional to global, and solutions require long-term planning at different levels of governance. This is nicely reflected for instance in the Gomes et al. article on drinking water in peri-urban communities in Bangladesh [7]. All authors point at the inherent complexity of water management, in similar terms, to come up with a clear need: to see the bigger picture.

\subsection{Stakeholders: Managing Competing Values in the Political Arena}

The water resource and distribution questions 'who gets what, when and how, and at what costs' is rife with controversies and prone to cause conflict. The arena of water management consists of 
actors who play in their own interests, within or against the rules. On top of that, there are sector and stakeholder interdependencies, power balances and so on. Institutions in charge of water management are multi-level and sectoral, which may stand in the way to integral approaches. Nearly all field studies emphasize that water management relies on stakeholder collaboration. The article by Marini et al. nicely address the competing values of stakeholders and how games should take this into account-by going beyond self-interest [5]. The question of course remains whether we can expect such magic from playing a game.

\subsection{Uncertainty: Operating at the Science-Policy Interface}

One aspect of complexity is uncertainty about the impact of human activities on future states. Uncertainty can have many reasons, such as unavailability or incompleteness of data, imperfect calculation and simulation models, human incomprehension and limitations to science. How is evidence from science brought into a stakeholder driven and political process? This is reflected in the papers on how games work at the science-policy interface [4] and understanding games as planning support systems [5]. One of the challenges in serious games, is how to connect playful interaction with data, realistic models and simulations into the game. Several papers $[9,10]$ demonstrate the integration of data, simulations and games.

\subsection{Reality as a Game: Reshaping Rule-Based Interactions}

Some theories suggest that water management can be looked at as a game. See for instance the paper by Gomes et al. that starts from game-theory [7]. At best, the zero-sum (win or lose) game is reshaped by the actors, to facilitate the sharing of the natural resource to prevent its imminent depletion. The rules of the game are formed by legislation, institutions (politics, economics) and culture. This game of course is bounded by the laws of nature (hydrology, ecology) although lack of understanding, insufficient data and uncertainty, gives room to play with that also [9]. If water management is like a game, the quality of the outcome depends upon the rule-based interactions among the players [8]. All field studies approach the serious games from the perspective of reshaping the rules for stakeholder-player interactions.

\subsection{Social Learning: Instrumentation and Tooling}

One strand of theory suggests that the quality of interactions among the stakeholders relies on what the stakeholders understand about the system, each other and the relationship between the rules, interaction and outcomes. In other words, the game of water management can be changed through social learning among the players. In this regard, others have claimed that communities of practice, simulations and games can be the tooling for that. Several papers, such as by Marini et al. [5] and Aubert et al. [1] stress that we first need to understand better the nature of social learning in a context of water management, and how this connects to the design and use of games for learning. One of the main challenges is how to make stakeholders learn. What are the best practices? The articles in the Special Issue give some clues and answers, but a coherent conceptualization still needs to be developed.

\subsection{Learning from Practice: Evidence-Based Serious Gaming}

A follow-up question is: how do we assess the effectiveness of the interventions aimed at social learning? How do we know what works, and under what conditions? A systematic scientific assessment of game-based approaches is essential to develop a deeper understanding of how and why a game-based approach fulfills the purpose and objectives it was designed for in the first place [1]. It is important to distinguish studying whether game-based approaches have worked (i.e., practice evaluation) from studying why and how game-based approaches have (or have not) worked (i.e., theory-based research assessment). In order to study and understand why and how a game-based approach has (or has not) worked, it is essential to use theoretical frameworks. Several authors make this point. 


\subsection{The Innovation Potential: Data, Intelligence and Immersion}

We live in a data- and media-rich world, with emerging technologies giving possibilities to shape new forms of interaction. Games are among them. How can we harvest the richness of emerging digital technologies (AI, media, games, VR, AR) to create new and better forms of interaction for the good of society? A few articles take a digital, immersive turn $[5,9,10]$, but this can be expected to become a stronger line of development in games for water management. In the contributions, the games are straightforward and practical. Board games and role-playing are predominant. One or two papers report on the use of advanced game technologies, such 3D and game engines. VR/AR in combination with big data and AI was not used. Perhaps at the time of publication, the technology was not advanced enough. It is likely that innovations in this area are reported from the engineering, design and validation perspective.

\section{Future Directions}

A more critical and reflective discussion of the limitations and even restrictions of games for social learning is necessary. The following points give directions for future research.

\subsection{Risk of Saturation}

We know remarkably little about who plays serious and persuasive games, how many people play them, why they play them, and what this delivers. When so many organizations launch persuasive and serious games in the area of sustainability, the target audience may get weary of them. The young generation is very demanding in terms of game-play. Not all of the games developed can be of equally high quality. In an educational context, students may take the wrong message.

We firmly believe that games can be powerful tools, but they should be used wisely and modestly; or they may turn against us. Game research can help to guide where and how it is wise to use them, and where not. A more critical and realistic view on serious games is needed. Perhaps we should develop and use less of them but with better quality and more impact.

\subsection{Ethical Considerations and Power Imbalance}

There has been serious neglect of the ethical considerations of developing and using games to induce change, especially among vulnerable target groups, such as children, excluded or disempowered groups in society. Like all forms of participation, the question can be asked: who is invited to play these games and thus, who is not? Power may come from different sources but having access to capital and control over natural resources is an important one. The games for a social learning paradigm suggest that a structural power imbalance can be overcome by interaction and that this creates mutual understanding. However, for this to happen an inherent rationality of the players, as well as equality and fairness in the game-play, is necessary. When a fight over natural resources like water is played out hard, social learning through games can turn into manipulation. It may falsely suggest that a level playing field exist and a win-win solution can be achieved. As with any form of empowerment and participation, the stakeholder-players in a serious game may feel cheated upon.

We therefore believe that social learning with or without serious games should not only be studied through social psychology, design and engineering, but also through ethics and political theory: power, participation and discursive-deliberative democracy are suggested starting points for further research.

\subsection{Pitfall of Mistaken Identity}

The social learning paradigm is heavily based on a constructivist world view. However, in sustainability, the realism part-evidence, data and science-is equally important. The combination of social learning and games may lead to negotiated nonsense. What happens if the 'wrong' message is passed on through serious games? What if authorities or participant-players skew the point the simulation games are trying to make? What if the players take the simulation game 'too literally' and 
cannot distinguish fact from fiction? What if the simulation games are not real enough and are only perceived as an enjoyable exercise after which everyone continues to think and do as before? These questions are relevant to those who want to use games for social learning in sustainability. Moreover, the intervention models on which serious games are based are seldom explicated or critically examined. The methodologies for measuring the impact of serious games are not very well established. Negative results and experiences with serious games are not reported.

We believe that a stronger instrumentation theory of social learning is necessary, with evidencebased evaluations, and frameworks and methods to do so. This is important because the use of even more immersive technologies, such as VR and AR, big data and intelligence for sustainability and natural resource management are around the corner.

Author Contributions: All authors contributed to recruiting and reviewing papers for this editorial. W.M. primarily led and coordinated this effort. I.M. and W.M. have written this editorial with input of the other authors.

Acknowledgments: Thanks to all of the contributions to the special issue, as well as to the anonymous reviewers who have contribute to the development of the articles. This special edition is the result of a Partnership Development Project funded through the Social Sciences and Humanities Research Council of Canada (SSHRC) Partnership Development grant (SSHRC 890-2014-0056) held by Jan Franklin Adamowski and contributed to by each of the guest editors of this special edition.

Conflicts of Interest: The authors declare no conflict of interest.

\section{References}

1. Aubert, A.H.; Medema, W.; Wals, A.E.J. Towards a framework for designing and assessing game-based approaches for sustainable water governance. Water 2019, 11, 869. [CrossRef]

2. Galván-Pérez, L.; Ouariachi, T.; Pozo-Llorente, M.; Gutiérrez-Pérez, J. Outstanding videogames on water: A quality assessment review based on evidence of narrative, gameplay and educational criteria. Water 2018, 10, 1404. [CrossRef]

3. Rodela, R.; Ligtenberg, A.; Bosma, R. Conceptualizing serious games as a learning-based intervention in the context of natural resources and environmental governance. Water 2019, 11, 245. [CrossRef]

4. Zhou, Q.; Mayer, I. Models, simulations and games for water management: A comparative q-method study in The Netherlands and China. Water 2017, 10, 10. [CrossRef]

5. Marini, D.; Medema, W.; Adamowski, J.; Veissière, S.; Mayer, I.; Wals, A. Socio-psychological perspectives on the potential for serious games to promote transcendental values in IWRM decision-making. Water 2018, 10, 1097. [CrossRef]

6. Magnuszewski, P.; Królikowska, K.; Koch, A.; Pajak, M.; Allen, C.; Chraibi, V.; Giri, A.; Haak, D.; Hart, N.; Hellman, M.; et al. Exploring the role of relational practices in water governance using a game-based approach. Water 2018, 10, 346. [CrossRef]

7. Gomes, S.; Hermans, L.; Islam, K.; Huda, S.; Hossain, A.; Thissen, W. Capacity building for water management in peri-urban communities, Bangladesh: A simulation-gaming approach. Water 2018, 10, 1704. [CrossRef]

8. Ferrero, G.; Bichai, F.; Rusca, M. Experiential learning through role-playing: Enhancing stakeholder collaboration in water safety plans. Water 2018, 10, 227. [CrossRef]

9. Sušnik, J.; Chew, C.; Domingo, X.; Mereu, S.; Trabucco, A.; Evans, B.; Vamvakeridou-Lyroudia, L.; Savić, D.; Laspidou, C.; Brouwer, F. Multi-stakeholder development of a serious game to explore the water-energy-food-land-climate nexus: The SIM4NEXUS approach. Water 2018, 10, 139. [CrossRef]

10. Khoury, M.; Gibson, M.J.; Savic, D.; Chen, A.S.; Vamvakeridou-Lyroudia, L.; Langford, H.; Wigley, S. A serious game designed to explore and understand the complexities of flood mitigation options in urban-rural catchments. Water 2018, 10, 1885. [CrossRef] 
11. Keijser, X.; Ripken, M.; Mayer, I.; Warmelink, H.; Abspoel, L.; Fairgrieve, R.; Paris, C. Efficacy of the MSP challenge board game for stakeholder engagement in maritime spatial planning. Water 2018, 10, 724. [CrossRef]

12. Jean, S.; Gilbert, L.; Medema, W.; Keijser, X.; Mayer, I.; Inam, A.; Adamowski, J. Serious games as planning support systems: Learning from playing maritime spatial planning challenge 2050. Water 2018, 10, 1786. [CrossRef]

(c) (

(C) 2019 by the authors. Licensee MDPI, Basel, Switzerland. This article is an open access article distributed under the terms and conditions of the Creative Commons Attribution (CC BY) license (http://creativecommons.org/licenses/by/4.0/). 